\title{
ArTEFACTO COMPUTACIONAL: ELEMENTO CENTRAL NA PRÁTICA ARTÍSTICA EM ARTE F CULTURA DIGITAL
}

\author{
Adérito Fernandes Marcos
}

\begin{abstract}
RESUMO
É discutida a emergência da arte digital e das suas diversas variantes tais como a arte computacional e a média-arte digital. E de como esta forma de expressão artística e cultural se vem afirmando numa contemporaneidade caracterizada pela revolução tecnológica digital. É analisada a natureza da criação e fruição da arte e cultural digital, as práticas artísticas relacionadas e como nestas, o artefacto computacional assume um papel central. Apresentam-se, em contexto, exemplos de artefactos, promovendo-se a sua recensão à luz da arte e cultura digital contemporânea, enquanto se discutem alguns elementos de uma estética dos artefactos computacionais.
\end{abstract}

\section{Palavras-Chave}

Artefacto computacional; arte digital/computacional; contemplação estética; cultura digital; média-arte digital

\begin{abstract}
The emergence of digital art and its various variants such as computer art and digital media art is discussed. As well as, how this form of artistic and cultural expression is being affirmed in a contemporaneity characterized by the digital technological revolution. It analyses the nature of the creation and enjoyment of digital art and culture, related artistic practices and how in these, the computer artefact plays a pivotal role. Examples of artefacts are presented in context, promoting their recension in the light of contemporary digital art and culture, while discussing some elements of an aesthetics of the computer artefacts.
\end{abstract}

\section{KEYWORDS}

Aesthetic contemplation;computer artefact; digital/computer art; digital culture; digital media-art

\section{DA EMERGÊNCIA DA ARTE DOS MEIOS DIGITAIS BASEADA EM ARTEFACTOS COMPUTACIONAIS}

A emergência da web (da expressão inglesa: World Wide Web) ou simplesmente rede, ocorrida a partir de meados da década de 1990, potenciou o acesso acelerado e massificado aos meios computacionais e comunicacionais, a uma escala global, o que lançou a sociedade contemporânea na aventura da denominada revolução tecnológica, cujos contornos e implicações, de cariz transversal e universal, na vida das pessoas, empresas e sociedade em geral, nos são ainda, e em larga medida, desconhecidos, facto necessariamente fruto, sobretudo, do acelerado desenvolvimento das tecnologias computacionais que não cessam de nos surpreender com novos e imprevisíveis resultados e conquistas. Vivemos hoje a era do pós-computador pessoal, que se transformou e 
multiplicou, gradualmente, em mais um simples nó da web global, de entre milhares de milhões de outros computadores espalhados pelo globo, onde cada nó se pode instanciar na forma de vários dispositivos ubiquamente acessíveis através de uma nuvem de dados e ligações, uma espécie de céu protetor que salvaguarda dados e ligações, privadas e públicas, onde uma parte significativa da população se conecta para comunicar, trabalhar e socializar, em redes e sub-redes crescentes de grupos de interesse, evoluindo para aquilo que se tem designado como a sociedade da informação e do conhecimento.

Neste cenário, os meios digitais constituem hoje uma parte fundamental da construção e sustentação dessa sociedade de informação, considerando aqui especialmente os dispositivos, a infraestrutura e a tecnologia computacional que permitem a geração (captura/sintetização), a transformação, a apresentação ou exibição e a comunicação da informação em formato digital (codificação de base binária). Os meios digitais, conjugados com as tecnologias da informação e da comunicação que permitem o seu processamento e comando, influenciam hoje fortemente, por exemplo, a forma como hoje compreendemos, criamos e consumimos arte e cultura, sobretudo quando corporizada em artefactos digitais/computacionais que se nos apresentam a partir de espaços informacionais/comunicacionais, convidando-nos à interação e ao envolvimento. Segundo dados recentes do sítio web eMarketeer', estima-se que 2,5 biliões de pessoas utilizam hoje o telefone portátil, sendo responsáveis pelo carregamento diário de mais de 300 milhões de fotografias para o Facebook, 40 milhões para o Instagram e 4,5 milhões para o Flickr. Estes espaços, sendo essencialmente de natureza puramente virtual, nascem associados a grupos de interesse, e são mantidos de forma espontânea e voluntária seguindo o processo natural da prossecução de um interesse comum tão em voga na colaboração em rede. Estes valores apontam para o fenómeno crescente, em evolução acelerada, da colaboração em rede, seja na geração ou na partilha de conteúdos digitais, atingindo hoje volumes gigantescos, geralmente de acesso livre, que constituem matéria prima basilar da criação artística em rede.

A arte digital, ou a arte dos meios digitais como também é referida, tal como a conhecemos atualmente, tem o seu advento nos meios artísticos nos finais da década de 1990, quando artefactos e instalações iminentemente de natureza digital começaram a ser incluídos nos programas dos eventos artísticos. Todavia, se atentarmos para a natureza da arte digital constatamos que esta sofre de influências que percorrem todo o século $X X$, retrocedendo até à década 10 e ao movimento Dada. De referir os artistas Dada, Marcel Duchamp ou László Moholy-Nagy, que desenvolveram os conceitos de virtualidade, volatilidade ou introduziram o recurso a outros sentidos, tais como o tato ou olfato, nas suas peças. O papel do espetador/fruidor ativo, que deixa de ser um simples observador para se assumir como observador-ator-interventor, aquele que interagindo, pode alterar o próprio artefacto artístico e o seu contexto de fruição, conceitos caros à atual arte digital/arte computacional, constituem características já intensamente exploradas pelos artistas Dada e pelos movimentos subsequentes. John Cage e Karlheinz Stockhausen desenvolveram os conceitos do controle baseados em instruções ou ainda

\footnotetext{
' Retirado de http://www.emarketer.com/Article/Smartphone-Users-Worldwide-Will-Total-175-Billion-2014/1010536
} 
a aleatoriedade controlada para gerar frases e composições musicais. Outros artistas e teorizadores pioneiros como Grahame Weinbren, Nam June Paik, Michael A. Noll, John Whitney, Vera Molnar ou Charles Csuri, para referir apenas alguns nomes, desenvolveram o conceito de acesso aleatório na geração de áudio e imagens sintetizadas pelo computador. Ray Ascott e Lev Manovich, mais recentemente, teorizaram sobre a interatividade e o papel dos média comunicacionais no processo de criação digital e na arte digital, computacional e interativa em geral. Estas características definem transversalmente a arte e a cultura digital e todas as suas variantes e especializações tais como a média-arte digital, estabelecendo em si os vetores de desenvolvimento de uma estética dos meios digitais (Marcos, Branco \& Carvalho, 2009, pp. 5-7; Paul, 2008, p. 27).

$A$ arte digital tem vindo a definir-se (e a impor-se) ao longo das últimas quase duas décadas como a arte produzida em ambientes computacionais digitais e que ela própria assume essa natureza, em que o processo de criação recorre ao meio digital/computacional como ferramenta e como matéria prima. A arte computacional assume uma definição mais vasta pois abarca genericamente toda a arte criada que se suporta através dos meios computacionais, não necessariamente de natureza digital. Já a média-arte digital reporta-se à especialização da arte digital em que a matéria prima base principal são os média ou os meios digitais, eles próprios, e a informação digital, onde a ênfase criativa é posta (não exclusivamente) na dimensão informacional-comunicacional do artefacto. O termo "média" reporta-se ao meio de comunicação ou difusão de informação sendo que média-arte digital se refere à arte criada e instanciada ou difundida recorrendo à média ou meios de comunicação/informação digitais. De referir que a expressão "digital" se reporta, neste âmbito, à natureza computacional de base binária do objeto, meio ou conteúdo do artefacto de arte digital (Lopes, 2010, p. 3).

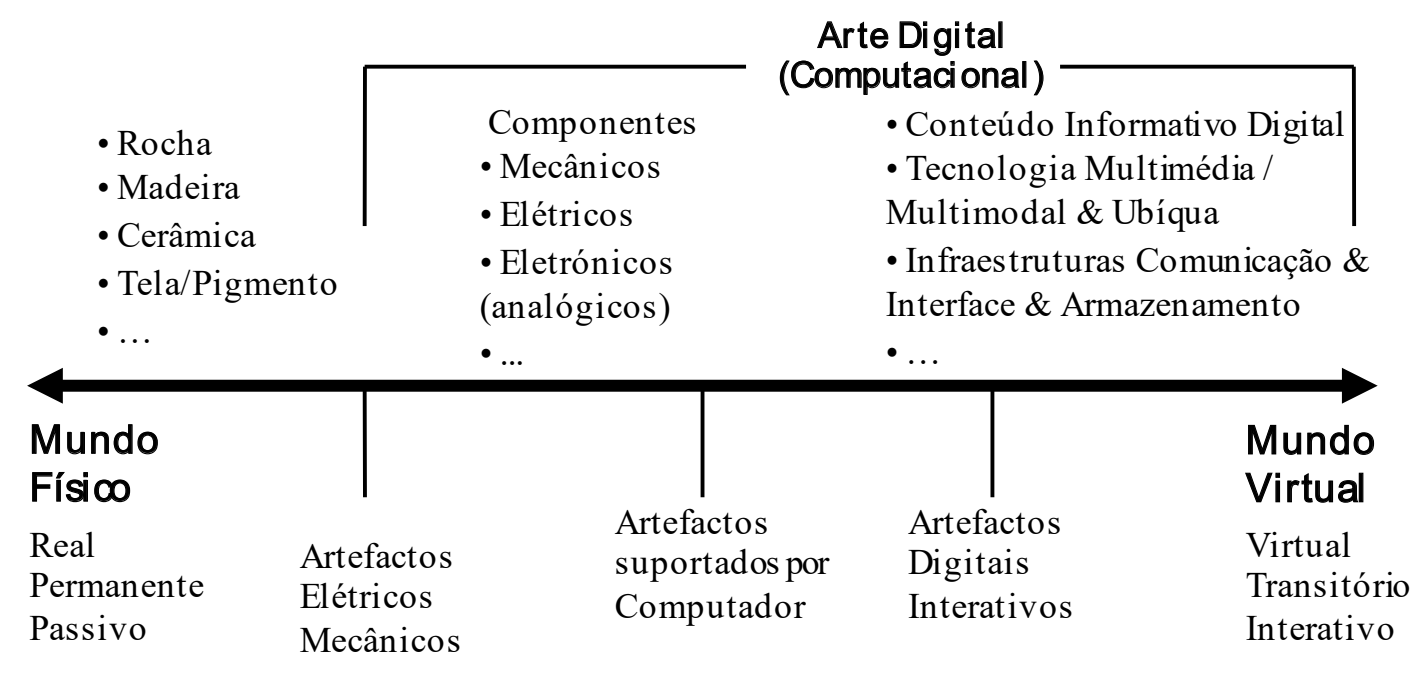

Medium Continuum da Arte

Figura 1: Representação do Medium Continuum Medium da Arte 
Na figura 1 apresenta-se uma representação do espaço de instanciação da arte, latu sensu, explorando o conceito de medium continuum ou meio contínuo de mediação da arte, que se situa entre dois mundos opostos, o mundo físico ou da fisicalidade tangível, aquele da representação física permanente, e o mundo virtual, transitório e intangível, que proporciona experiências interativas mediadas por meios computacionais digitais e virtuais. Localizamos a arte digital (computacional) próximo de e abarcando este mundo virtual digital. Os artefactos de arte e cultura digital localizam-se também nesta área do espaço medium continuum.

Na Figura 2 apresenta-se uma categorização geral, não exaustiva, da arte digital (computacional), baseado em três categorias fundamentais, nomeadamente:

- virtualidade: nível de migração da fisicalidade do objeto de arte, especialmente do seu conceito capital, para os espaços digitais virtuais, de natureza intangível, através de um qualquer meio de virtualização. O conceito torna-se percetível através da virtualização do seu objeto;

- interatividade: nível de interação/envolvimento possibilitado entre o utilizador/fruidor e o artefacto, um diálogo que pode levar à alteração do próprio artefacto;

- aleatoriedade: nível percebido de não-determinismo na instanciação do artefacto (ou de parte do mesmo) criado por algoritmia baseada em instruções previamente configuradas pelo artista criador ou pelo próprio público fruidor.

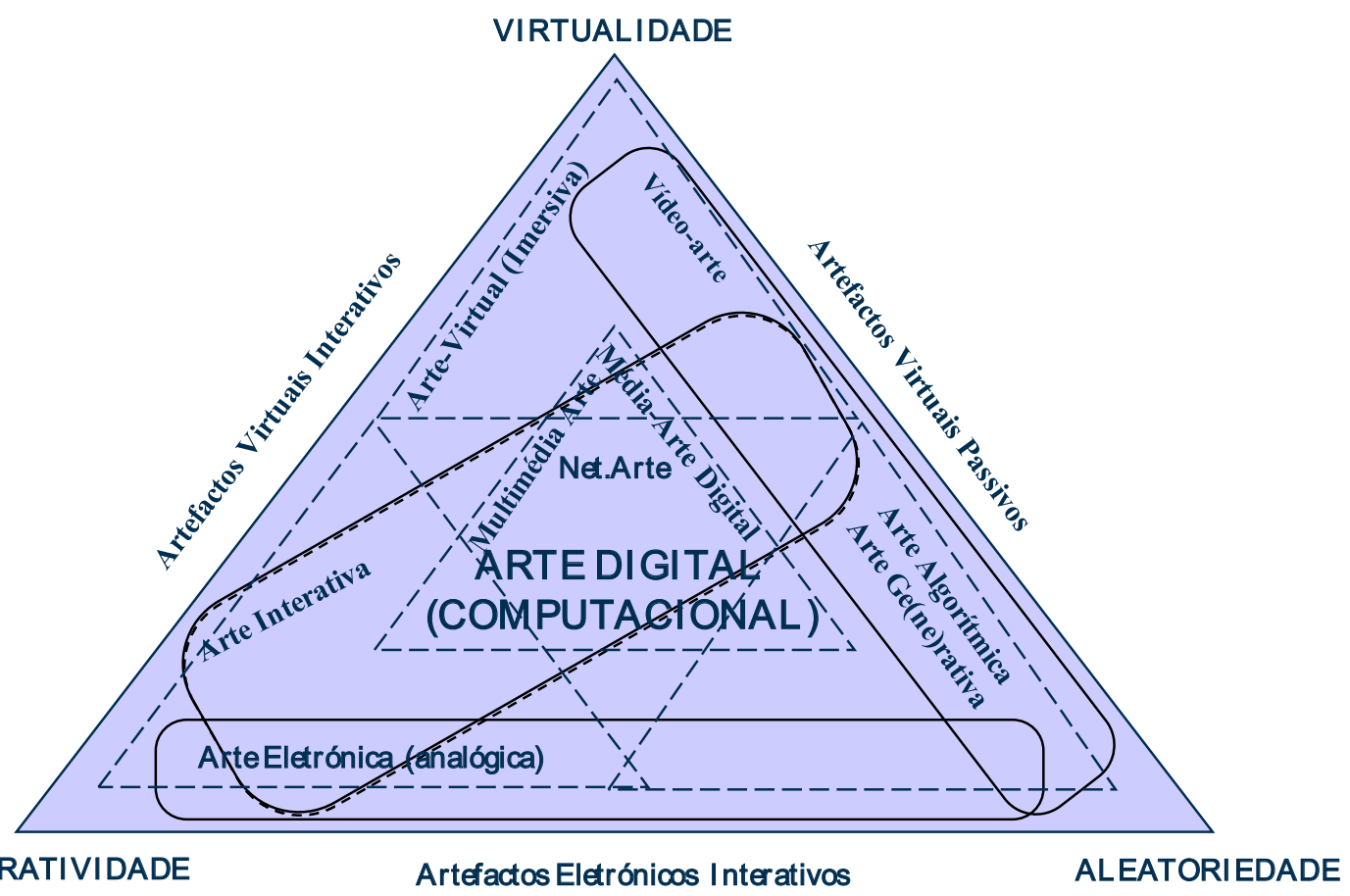

Figura 2: Uma categorização geral da arte digital (computacional)

Nem sempre é possível determinar com a adequada precisão as circunstâncias da utilização inicial de algumas das categorias referenciadas, já que experiências artísticas pioneiras no uso da tecnologia computacional (digital) foram acontecendo em vários espaços laboratoriais, um pouco por todo o mundo. Por exemplo, a arte computacional 
(computer art) terá tido a sua génese na década de 1960 por via dos investigadores/ criadores dos laboratórios Bell, Nova Jersey, nomeadamente, Michael A. Noll foi um dos pioneiros da produção de imagens sintetizadas por computador. A vídeo-arte aparece em meados dos anos 1960 quando o respetivo equipamento se tornou disponível aos criadores. Já a net.arte (ou web-arte ou internet-arte como também é denominada) aparece em meados da década de 1990 quando a Web foi apropriada como espaço de criação e difusão de arte, geralmente de natureza efémera e apenas acessível na rede, sendo o termo atribuído ao artista Vuk Cosic (Greene, 2005).

Os objetos de arte e cultura digital (computacional) ou de média-arte digital são artefactos de cariz digital (binária) ou computacional (abrangendo elementos computacionais não necessariamente binários) que aportam essencialmente uma natureza informacional, propondo-se potenciar experiências significativas ao observador/utilizador/fruidor, metamorfoseando, quiçá, também em interventor-(co)autor. Os autores procuram explorar amiúde nestes artefactos a interatividade e a expressividade, seja esta de cariz informacional ou comunicacional, transformando-os em indutores da ação-intervenção artística e cultural. Na sua essência mais marcante, estes artefactos não são apenas objetos para serem apreciados passivamente, mas acarretam características virtuais, eventualmente imersivas, potenciando a interação, levando o utilizador-fruidor a encetar uma viagem de contemplação estética de natureza polissémica, em múltiplos cenários de uso e fruição que vão desde a educativa, científica, lúdica, filosófica ou mesmo a sagrada, o que pode estimular a realização de experiências qualitativas, de natureza inter-, multi- ou mesmo transdisciplinares quando vários saberes se entrecruzam e complementam para gerar apreensões de natureza complexa.

Define-se experiência significativa aquela em que o sujeito classifica como importantes, relevantes e gratificantes os seus contributos, podendo estes revestir-se de diversas índoles (estético-contemplativo, educativo, lúdico-entretinimento, histórico, social, etc.).

\section{Do CICLO DE CRIAÇÃo E FRUIÇÃo DE ARTE E CULTURA DIGITAL}

Dada a natureza dos meios digitais que constituem tanto a ferramenta de criação como a matéria prima da arte digital, o ciclo de criação dos artefactos digitais herda naturalmente características próprias do processo de desenvolvimento dos artefactos computacionais, abarcando aspetos intrinsecamente relacionados com a criação/configuração dos sistemas e aplicações informáticas.

O ato de criação artística, ou o processo de criação em si, tem sido objeto de muito debate e pesquisa nas últimas (muitas décadas), mesmo considerando que as questões relacionadas com a arte e a beleza foram tema de análise já na Grécia antiga, por Platão e Aristóteles, por exemplo. Por exemplo, Duchamp na sua aula intitulada "The Creative Act" (Duchamp, 1966) afirma que o artista nunca se encontra só com a sua obra; existe sempre um observador/espectador que mais tarde irá reagir criticamente à obra apresentada. É comummente aceite a ideia que, se o artista tiver sucesso na transmissão do 
seu propósito inicial através da mediação da sua obra/artefacto, seja esta uma mensagem, emoção ou sentimento, reflexão, etc., assumindo a forma de uma experiência significativa, então um processo de osmose estética tem lugar através do artefacto (o meio), considerando todas as suas partes constituintes, sejam estes material inerte ou componentes digitais, por exemplo, no sentido em que permite que a referida experiência aconteça, acaso potenciando a contemplação estética (Eco, 1962; Grau, 2003; Marcos, 2012).

O processo de criação em arte e cultura digital orienta-se geralmente para o desenho da mensagem e da experiência que se visa proporcionar através do artefacto e do seu desenvolvimento físico. O meio computacional, aqui considerando as ferramentas de edição, design, programação, comunicação, colaboração em rede, etc., assim como os conteúdos informativos digitais e as infraestruturas, sustenta todo o processo de criação. O processo de desenvolvimento das componentes computacionais do artefacto segue em grande medida os procedimentos adotados no desenvolvimento de sistemas e aplicações informáticas, de pequena e média escala. No entanto, contrariamente ao processo tradicional de design onde a resolução de um problema guia a ação do designer, em arte digital a sistematização não aparece primariamente para esse fim, mas sim para potenciar o propósito final do artefacto, isto é, proporcionar a experiência significativa de contemplação estética que advém da fruição do artefacto.

Apesar dos artistas adotarem geralmente um processo similar na prossecução do seu engenho criativo, isto é, partem de um conceito ou ideia inicial que pode eventualmente evoluir, em ciclos de avanço e recuo, até ao artefacto final, constata-se também que tal não acontece de forma sistematizada consciente, mas sim aleatória e espontânea (Quintas, Marcos \& Tavares, 2015, p. 82). A fase zero do processo de criação, ainda antes de qualquer conceito inicial ser adotado, é preenchida pela experimentação de tecnologia, compilação de ideias, leitura e aquisição de conhecimentos e competências técnicas específicas. E então, gradualmente um aspeto particular sobressai e ganha preponderância, transformando-se no centro da experimentação e da reflexão, dando indicações para o desenho do futuro sistema ou aplicação, ou ainda da experiência a proporcionar ao fruidor, a partir do qual, vários caminhos alternativos de evolução se colocam, alguns serão tentados, seguidos ou abandonados, no sentido de gradualmente atingir instancias mais refinadas, sendo uma das quais (ou grupo delas) escolhida para suportar a experimentação e o desenvolvimento continuado até ao artefacto final (Marcos et al., 2009, p. 16).

O processo de criação em arte e cultura digital tende para ciclos de intensa reflexão e de apreensão acerca da natureza e potencial criativo oferecido pela tecnologia e os meios digitais/computacionais. Marcos afirma sobre o ciclo de criação:

de facto, uma das atividades centrais do processo de criação em arte (e cultura) digital é a meditação estética, que representa os momentos de contemplação onde o artista revisita a sua visão inicial à luz das decisões tomadas (ou em vias de tomar) durante as fases de desenho e implementação do artefacto e estabelece com este uma relação interior profunda. 
Esta reflexão estética conduz-se por dois vetores fundamentais, a saber, a apreensão estética relacionada com a necessidade de proporcionar uma experiencia percetiva de prazer, sentido ou satisfação (ou outras); e a inovação tecnológica que abarca as questões da exploração das características de maior potencial da tecnologia, no sentido deste poder efetivamente funcionar como força condutora/indutora para a criação de novos discursos estéticos. (Marcos, 2012, p. 140)

O artista ou criativo em arte e cultura digital imerge numa viagem de intensa reflexão, que resulta do amadurecimento gradual da sua visão primordial (theoria), da experimentação prática com as tecnologias e os materiais (praxis) e da construção efetiva ou materialização de protótipos de e do próprio artefacto (poesis) enquanto no cenário de exposição, uso e fruição. Trata-se de uma viagem prenhe de conflitos e questionamentos interiores, face ao processo, os materiais, a ideia primordial e o público. A prática tem-nos ensinado que quanto mais profundo for o processo de reflexão-experimentação-construção (materialização) levado a cabo pelo criador, realizado com os tempos adequados, que incluem pausas e períodos de intensa atividade, maior será a propensão para atingir resultados de elevada qualidade estética na perspetiva da experiencia proporcionada (Marcos, 2012, p. 142; Marcos \& Zagalo, 2011, p. 147).

Gianneti alerta-nos para o facto de o ciclo de criação tender a afastar-se do objeto final, o artefacto, como o epicentro do processo de reflexão estética, para se reorientar para o processo em si, o sistema, as tecnologias e o contexto, este último, o espaço-tempo em que experiência de fruição terá lugar. Giannetti afirma:

é necessário buscar formas de pensamento e experiências diferentes, que permitam a assimilação e a análise - nunca a negação - dos fenômenos contemporâneos. A prática e a teoria da media art e, especificamente, da arte interativa permitem o entendimento dessas novas formas. Esse campo artístico parte de algumas premissas essenciais, que originam novas conceções: a reação contra a teoria estética centrada no objeto de arte e favorável à reflexão sobre o processo, o sistema e o contexto; a ampla interconexão entre as disciplinas; e, finalmente, uma redefinição dos papéis do autor e do observador. (Giannetti, 2012, p. 6).

Por outro lado, o ciclo de criação abre-se, naturalmente, à colaboração em rede, entre grupos de interesse, conjugando diferentes conhecimentos e disciplinas, face às especificidades tecnológicas, expositivas, entre outras, exigidas no desenvolvimento do artefacto.

A Figura 3 apresenta o aspeto geral do ciclo de criação em arte e cultura digital/ computacional. O ciclo de criação inicia-se quando o artista/criativo lança um conceito/ ideia de partida, ainda que inconsciente desse facto. Esta fase pode ser antecedida de momentos de experimentação tecnológica livre onde o artista procura a apropriação das potencialidades e limitações dos meios computacionais (ferramentas, aplicações, 
sistemas, etc.), que considera potencialmente essenciais à implementação da sua visão primordial.

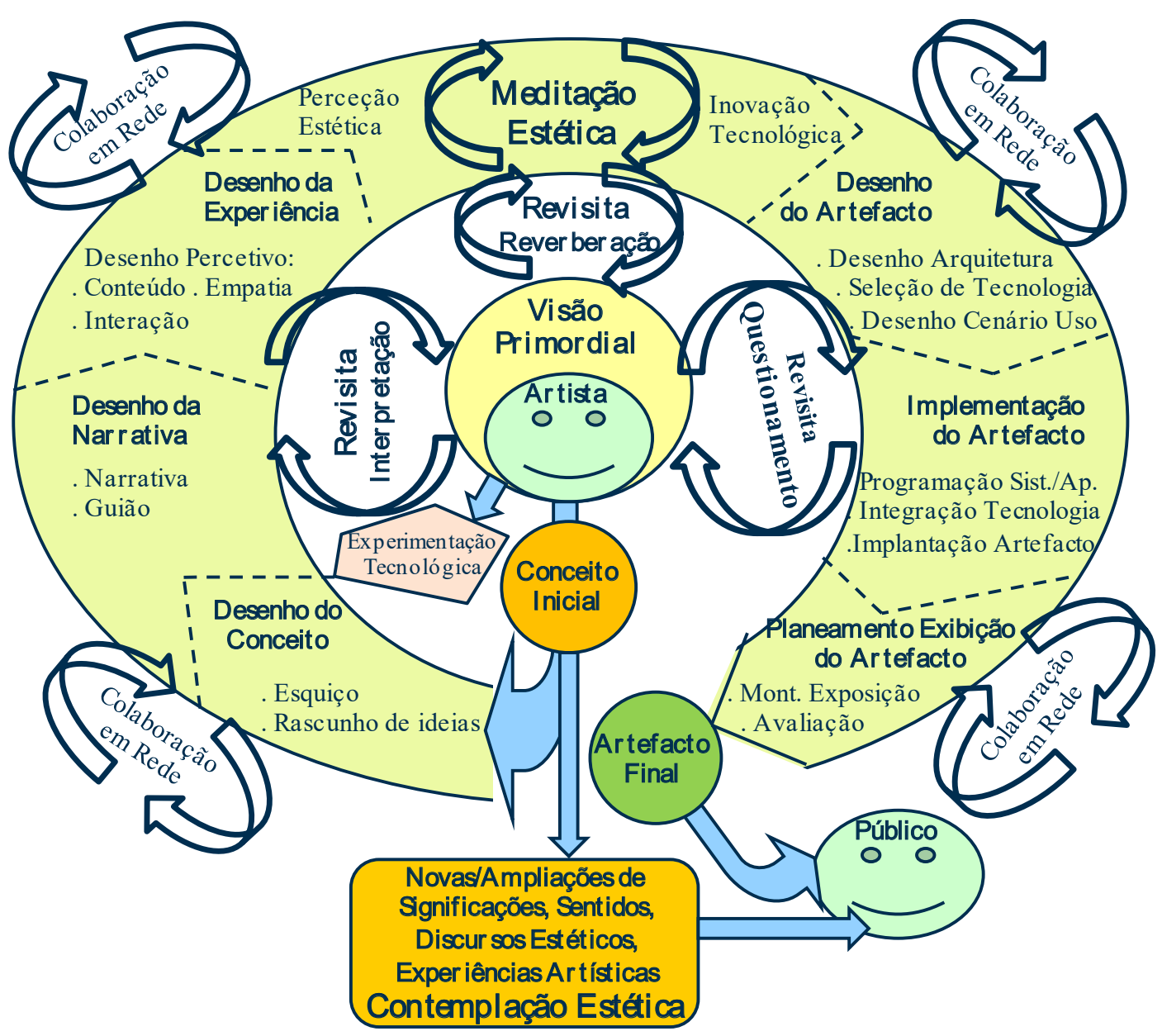

Figura 3: O ciclo de criação em arte digital (computacional)

Existem várias fases do ciclo de criação, cada uma contribuindo com componentes fundamentais para a construção do artefacto final. Nomeadamente:

\section{Fase de Desenho da Mensagem:}

- Desenho do Conceito: abarca a conversão da ideia/conceito em esquiços, desenhos informais, i.e., a abstração concretiza-se numa estrutura tangível, mas ainda em perspetiva. Trata-se de uma fase de pura exploração, onde não se pretende qualquer trabalho final.

- Desenho da Narrativa: em posse dos resultados da atividade anterior, concebe-se uma composição, uma sequência de eventos que permita arquitetar a mensagem através do envolvimento do espetador/utilizador através de uma narrativa suportada pelo próprio artefacto. A narrativa assume a forma de uma sequência cronológica de temas, motivos e linhas de enredo. O resultado desta atividade suportará um maior ou menor envolvimento do espetador/utilizador em uma determinada narrativa ou história que instancia a própria mensagem geral do artefacto. 
- Desenho da Experiência: abarca a conceção de características a imprimir a cada evento da narrativa para que esta possa proporcionar ao espectador/utilizador uma determinada experiência. A conceção ou planeamento desta experiencia, em cada evento da narrativa, é realizada levando em linha de conta preceitos individuais ou de grupo, conhecidos ou suspeitados, ao nível das crenças, emoções, conhecimento, habilidades, experiências e perceções.

- Meditação Estética: esta atividade assume um papel fulcral no ciclo de criação, pois representa os momentos de contemplação onde o artista/criativo revê, revisita a sua visão seminal à luz das decisões tomadas (ou apenas planeadas) (ver Figura 3) durante o desenho e desenvolvimento do artefacto. Identificam-se dois vetores condutores nestas atividades, a saber:

- Perceção Estética: processo de reflexão e conceção da integração de características no artefacto que facultem experiencias de prazer, significação ou satisfação (ou outras), provindas especificamente de manifestações e estímulos sensoriais gerados a partir do artefacto por via da sua forma, cor, imersão sensorial, som, textura, design ou ritmo, entre outros. A dimensão estética aqui relaciona-se exclusivamente com a natureza percetiva dos vários componentes do artefacto.

- Inovação Tecnológica: processo de reflexão e conceção de aspetos inovadores na (re)modelação, utilização, combinação e exploração da tecnologia que forma e substantifica o artefacto. Tal aponta para a dimensão estética dos meios computacionais, para a criação de novos discursos estéticos suportados e potenciados por estes, onde a virtualidade, interatividade e aleatoriedade, jogam um papel primordial.

\section{Fase de Desenvolvimento do Artefacto (ver Figura 3):}

- Desenho do Artefacto: abarca o desenho do sistema ou aplicação computacional, considerando todos as suas partes, de qualquer índole (mecânico, eletrónico, materiais, etc.), que irão instanciar o artefacto final. Inclui o desenho da arquitetura, da interface e da interação do sistema, assim como a seleção de tecnologia para a sua implementação ou ainda a conceção e desenho do cenário de exposição ou fruição.

- Implementação do Artefacto: abarca a implementação concreta do próprio artefacto. Esta atividade integra tarefas tais como a programação de sistemas e aplicações, teste e debugging, assim como, integração de tecnologia e a implantação final do artefacto como obra terminada, podendo ser realizada com o apoio de uma equipa interdisciplinar de informáticos e artistas digitais.

- Planeamento da Exposição do Artefacto: abarca as questões relacionadas com o planeamento e a montagem da exibição do artefacto. Trata-se do estágio final da concretização da obra, onde o artefacto é disponibilizado perante um determinado público. Esta fase inclui aspetos relacionados com a organização do espaço de exposição, a logística das diferentes componentes, ou a contextualização/integração do artefacto no todo da exposição, de acordo com um determinado plano curatorial.

O ciclo de criação em arte e cultura digital suporta-se, portanto, em dois subciclos fundamentais que demarcam a reflexão-ação contínua levada a cabo pelo artista/criador: o desenho da mensagem e o desenvolvimento do artefacto, mediado pela atividade de meditação estética, entrecruzando-se com os momentos em que o artista revisita a sua ideia primordial confrontando-a com o ciclo de criação, no estado em que se encontra, com os materiais e as ferramentas, e até, se já em fase de implementação e teste do protótipo do artefacto, com os observadores/utilizadores/fruidores.

A meditação estética implica uma postura de contemplação ou reverberação acerca dos motivos/motivações mais profundas e intrínsecas face ao sentido/significação do artefacto almejado, numa perspetiva que se enforma, comummente, de cariz 
interventivo. A meditação estética representa aqui ainda a conceção e criação de mecanismos de questionamento do mundo através de um processo de interação com o artefacto em desenvolvimento para (re)criar significados ou reforçar sentidos, podendo abraçar a pesquisa pela inovação tecnológica na senda dos novos discursos estéticos computacionais-digitais, vetores de exploração que possam abrir portas para novas perceções, em última instancia, novas experiencias artísticas e de contemplação estética seja para o criador ou criadores do artefacto mas, sobretudo, para público consumidor (Marcos \& Zagalo, 2011).

\section{DOS EXEMPLOS DE ARTEFACTOS COMPUTACIONAIS EM ARTE E CULTURA DIGITAL}

A arte e cultura digital substancia-se na interação social, da manifestação do imaginário individual e coletivo, através dos artefactos, que coexistem em um espaço informacional e comunicacional comum suportado nos meios e infraestruturas digitais. Estes artefactos representam a expressão maior do nosso imaginário comum no seio de uma contemporaneidade que se confunde na sociedade de informação.

Routio (2003) apresenta a ciência dos artefactos, ou arteologia (da expressão inglesa arteology), recorrendo à conjugação de "ars" do latin (arte, técnica) e do grego "logos" (trabalho, conhecimento). A arteologia estuda a semiótica dos artefactos, de qualquer natureza, sua funcionalidade e usabilidade, beleza, a mensagem e a envolvência, processos de investigação e categorização, entre outros. Propõe assim, o estudo comparado de vários artefactos no sentido de ajudar a compreender a atividade inerente à sua produção, os seus processos de criação e os seus criadores, promovendo assim o desenvolvimento e o avanço do estudo dos artefactos latu sensu. Routio analisou em detalhe aspetos como a diferença de expetativas e como tal pode estar na origem na diferença de experiências que um determinado artefacto pode mediar:

se o observador de uma obra de arte tem uma expectativa, a sua impressão da obra raramente irá corresponder exatamente à expectativa original. A diferença pode ser chamada de diferença de expectativas. Se esta diferença é muito pequena, o resultado será que o trabalho gerou uma impressão trivial. Se, no entanto, a diferença é muito grande, a obra de arte pode permanecer totalmente incompreensível. Somente quando uma obra de arte difere das expectativas dentro de um determinado nível adequado, é que a impressão estética final se torna positiva e satisfatória para o observador. (Routio, 2003, p. 355)

O que Routio denominou de diferença adequada de expectativas em uma certa obra de arte ou artefacto é assumido na presente reflexão como a realização de uma experiência significativa de contemplação estética facultada pelo respetivo artefacto. Esta diferença de expetativas depende também da experiência prévia e especialização que o observador/fruidor possui, relativamente a trabalhos similares. É óbvio que especialistas e profissionais de qualquer área de arte têm expectativas mais amplas e muito mais detalhadas do que os não especialistas ou leigos. Estas diferenças de expetativas explicam 
também as diferenças de atitude na apreciação da arte que encontramos usualmente entre o grande público e a crítica.

Apresentam-se de seguida três artefactos representativos de arte e cultura digital.

\section{Artefacto Tapete Interactivo "Óbidos/Oppidum"}

Os computadores ditos vestíveis, da expressão inglesa wearable, permitem transformar as peças de vestuário em componentes de um sistema informático com maior ou menor complexidade, estabelecendo novas linhas de desenvolvimento e reflexão na área do design de moda, da performance e expressão corporal, enfim, na utilização do corpo como mediador de intervenção em arte e cultura digital.

O artefacto Tapete Interactivo "Óbidos/Oppidum" de Barradas et al. explora as possibilidades do embebimento de sensores e minúsculos computadores nos tecidos, também referidos como $e$-materiais, sendo estes programáveis para a recolha de informação de natureza diversa sejam estes sinais fisiológicos, sinais do meio ambiente tais como a temperatura, luminosidade, etc. Estes tecidos de alta tecnologia podem configurar um vestuário com potencial de alterar a sua forma e aparência, absorver o impacto, reconfigurar as superfícies e as temperaturas, entre outros (Barradas, Coelho \& Tavares, 2014, pp. 74-76; Quinn, 2012).

O Tapete Interactivo "Óbidos/Oppidum" é um artefacto digital em têxtil, que estuda a interação dos e-materias com a técnica tradicional da tapeçaria. De acordo com os autores, a escolha de um tapete e não um artefacto vestível, surgiu como resposta à chamada para realização de um projeto alusivo à vila portuguesa de Óbidos.

O artefacto exibe um grafismo estilizado do castelo de Óbidos, onde se pretendem impulsionar, através dos e-materiais, a redescoberta de técnicas tradicionais e propor novas leituras do objeto tapete, apresentando-o como uma tapeçaria contemporânea, assumindo uma dimensão mais estética que prática, relevando o papel do artesão como artista.

O utilizador pode interagir com o artefacto alterando a sua configuração luminosa e espoletando sinais de natureza sonora-musical. Propõe-se uma desconstrução da lógica imóvel e estática do tapete tradicional para permitir a sua reinvenção através da linguagem visual-sonoro-musical interativa, introduzindo-o no imaginário dos objetos de arte e cultura digital. O diálogo entre o fruidor e o artefacto acontece através de ações de proximidade sobre os componentes eletrónicos que constituem os e-materiais embebidos nos tecidos do tapete. Nas Figuras 4 e 5 apresentam-se imagens do artefacto, categorizado mais pela dimensão da interatividade e menos da virtualidade. 

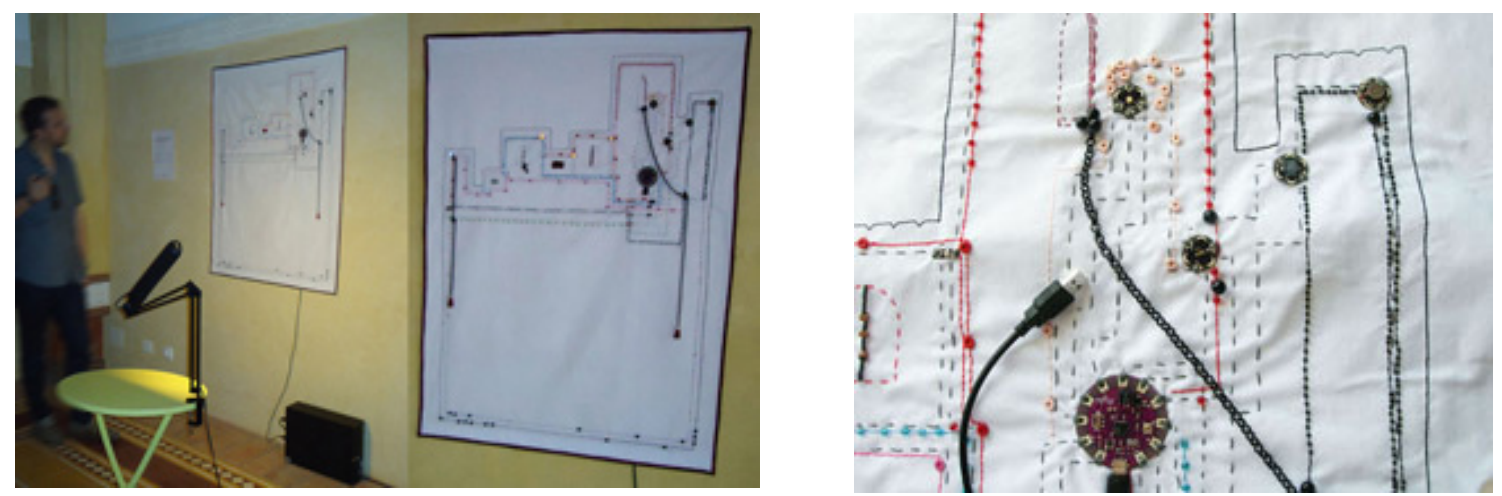

Figira 4: Vista geral (esquerda) e pormenor do artefacto (direita)

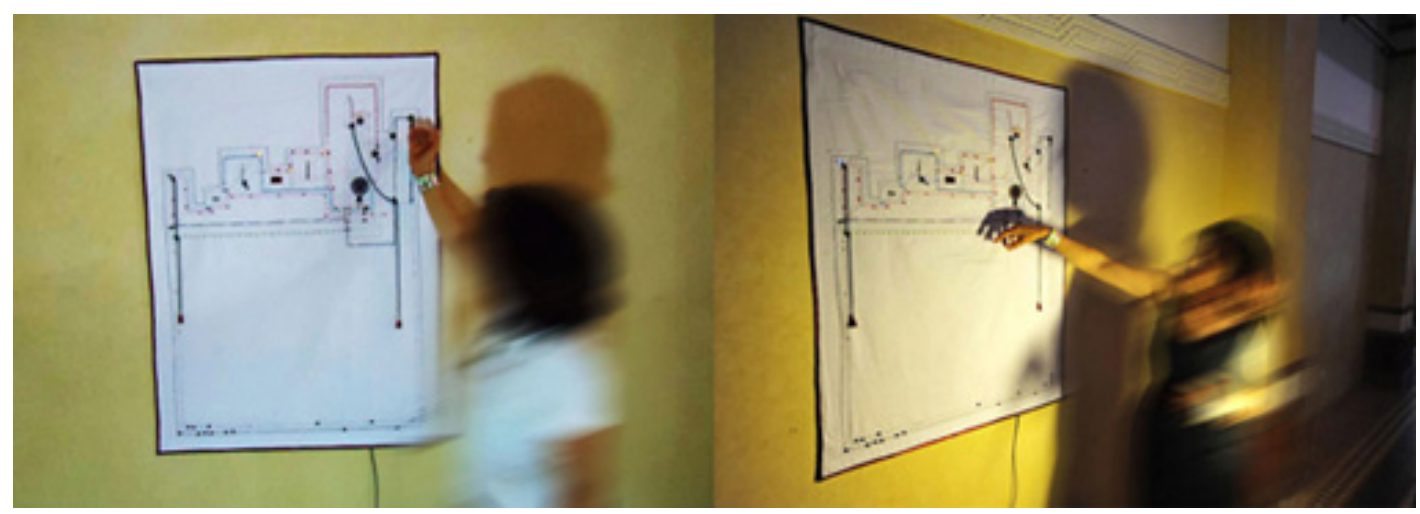

Figura 5: Interagindo com o artefacto

\section{Artefacto "Escultura Présence"}

A arte sonora (da expressão inglesa sound art) é uma prática artística onde o artista materializa a sua ideia primordial através do som. A arte sonora consolidou-se a partir do final da década de 90, manifestando-se através de várias exposições em galerias e museus, apesar do termo ter surgido na década de 1960 (Cox 2009, p. 22).

O artefacto "Escultura Présence" de Quintas, Marcos e Tavares (2015) recorre aos princípios da arte sonora para explorar o conceito dos retratos sonoros dos utilizadores. Os retratos sonoros resultam de coreografias espontâneas onde o utilizador gera composições sonoras eletrónicas que o identificam de forma única, a partir dos movimentos corporais que realiza, e que são registados juntamente com o conteúdo sonoro. Este conjunto representa um retrato único do utilizador enquanto interventor em um determinado espaço físico (Quintas et al., 2015, p. 5).

O artefacto "Escultura Présence" integra um sistema interativo de composição sonora que proporciona experiências sensoriais ao nível da audição e do movimento do corpo. A experiência é sonora, pois baseia-se na geração em tempo real de uma composição de música eletrónica; mas é também corporal e gestual, já que requer o movimento corporal e gestos do utilizador-fruidor, que imerge em uma dimensão performativa e coreográfica de autorrepresentação (autorretrato sonoro). Na Figura 6 apresentam-se as componentes principais do artefacto. 

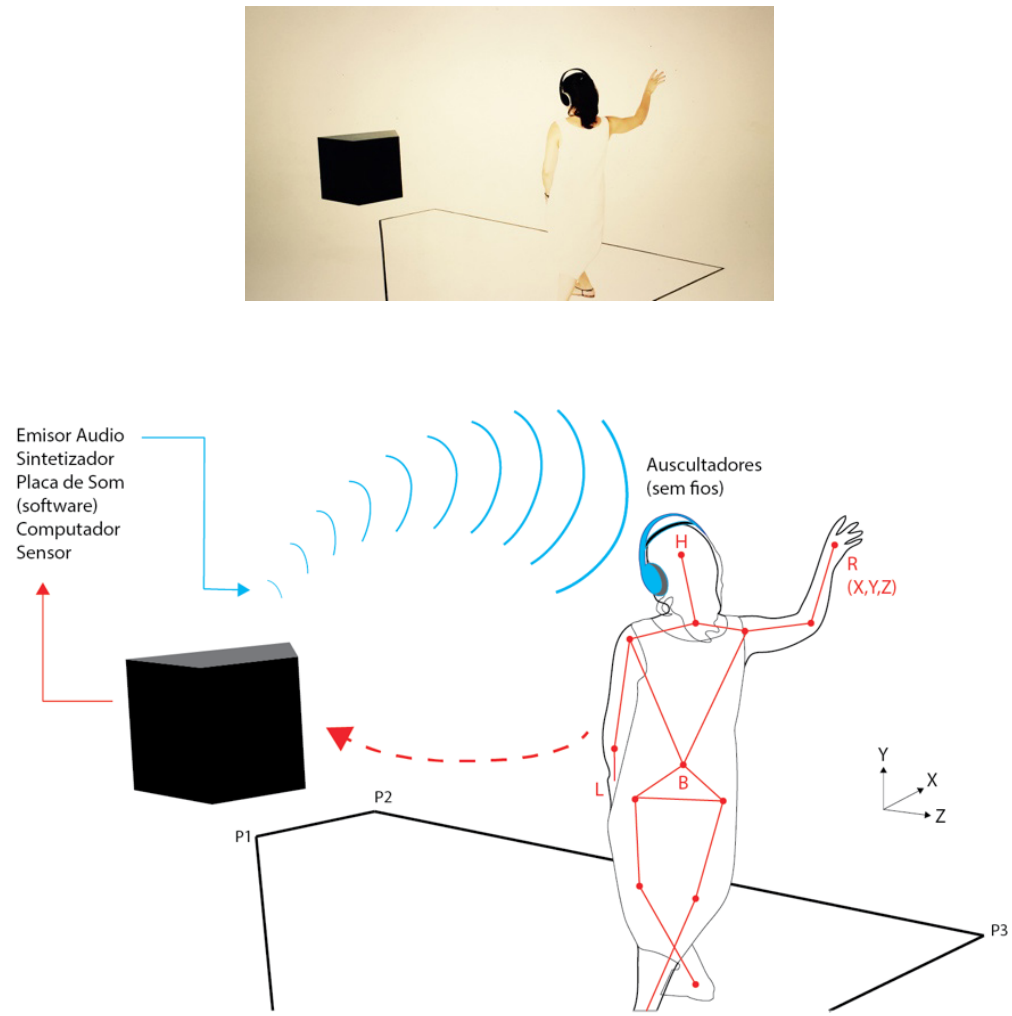

Figura 6: Interagindo com o artefacto (em cima). Esquema do fluxo informativo principal do sistema (em baixo)

O sistema foi desenvolvido para oferecer uma interface intuitiva e responsiva vocacionada para o público em geral. Os fruidores podem vivenciar uma experiência sonora original, expressiva, mediada por computador, sem a necessidade de possuírem um conhecimento prévio em composição musical ou aprendizagem da interface.
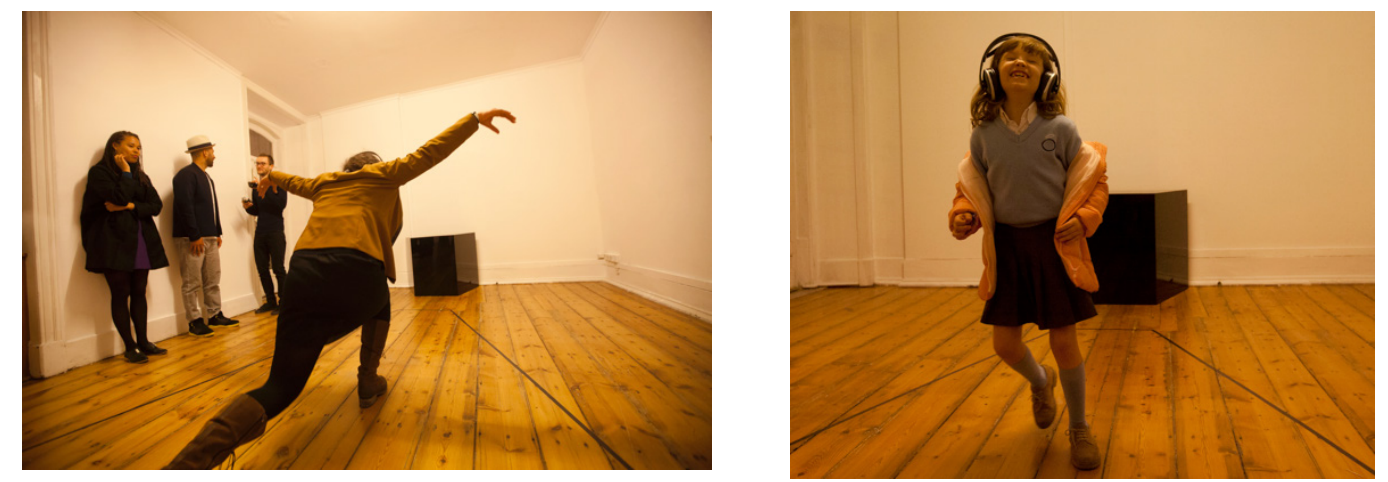

Figura 7: Participantes a vivenciar a escultura na galeria Adamastor Studios, Lisboa

O artefacto foi amplamente exposto e fruído, em vários espaços e contextos, permitindo aferir de uma extensa diversidade de reações que, na sua esmagadora maioria, testemunharam experiências de índole poética e contemplativa. As opiniões, pensamentos e relatos orais e escritos registados, de mais de 500 participantes, revelaram, na sua 
quase totalidade, vivências profundamente pessoais, sobretudo no grupo dos cegos e amblíopes, como se o artefacto tivesse sido criado especificamente e pensar em cada um deles individualmente. A ideia primordial de retrato é assim alcançada através do conjunto cada coreografia e a correspondente composição sonora, representando, assim, uma transposição plástica e poética de cada individuo (Quintas et al., 2015, p. 12). $\mathrm{Na}$ Figura 7 apresentam-se exemplos de participantes em plena fruição do artefacto. De referir que este artefacto conjuga de forma vincada as três categorias dos artefactos de arte e cultura digital (interatividade, virtualidade e aleatoriedade controlada).

\section{Artefacto "Entre o Sagrado e o Profano nas Festas de S. João d'Agra"}

Anualmente, em plena serra d'Arga, serra localizada no Minho, norte de Portugal, têm lugar as festas ou a romaria de São João d'Agra, um evento de cariz religioso peculiar, já classificado como o mais excecional nesta categoria (Guerra \& Paulino, 2010, p. 131). Nestas festividades deparamo-nos com a convivência, uma espécie de promiscuidade simbiótica, entre as práticas sagradas e as profanas, ou seja, as procissões, as orações, missas, etc., por um lado, e por outro lado, a folia boémia feita de festas onde imperam os símbolos pagãos e os comportamentos primitivos como os duelos e lutas, os desafios, bebedeiras e comedeiras descontroladas, etc. Encontram-se peregrinos motivados tanto pela participação na dimensão mais sagrada, em honra de São João, considerando aqui literalmente como o sagrado institucionalizado, e aqueles que se deslocam ao local para as várias festas profanas que aí decorrem. Estabelece-se como que uma competição entre estes dois fluxos de peregrinos, que concorrem entre si pela posse do local e das respetivas festividades. É esta competitividade entre estes dois grupos que constitui o conceito primordial no artefacto "Entre o Sagrado e o Profano nas Festas de S. João d'Agra" (Dominguez el al., 2014, p. 4).

O artefacto "Entre o Sagrado e o Profano nas Festas de S. João d'Agra" desenvolve uma representação pictórica, dinâmica, que representa o local da romaria, que se vai alterando em resultado da interação do utilizador-fruidor que manipula um pêndulo, levando a que a representação do local se vá cobrindo de pequenos pontos de duas cores, que percorrem o espaço em fluxo e competição, simbolizando os dois grupos de peregrinos em confronto e simbiose, pois ambos são necessários para tornar realidade São João d'Arga.

O artefacto impele o utilizador-fruidor a explorar vários níveis de uma narrativa visual manipulando um pêndulo suspenso sobre a imagem do local, induzindo assim comportamentos dos diferentes peregrinos, gerando também informação sonora alusiva. Essas mudanças só são verificáveis se um dos dois eixos conceituais (sagrado ou profano) ganhar força à medida que o movimento de pêndulo específico o estimula, proporcionando não só uma experiência empírica baseada na simulação do confronto dos dois grupos de peregrinos, visível como um jogo, mas também, sobretudo, a experiência estética da construção do quadro pictural, uma narrativa visual, feita da combinação dos símbolos pictóricos dos peregrinos representados em confronto sobre figura base do local da romaria. As várias imagens criadas podem ser guardadas separadamente juntamente com o contexto de criação / interação. 


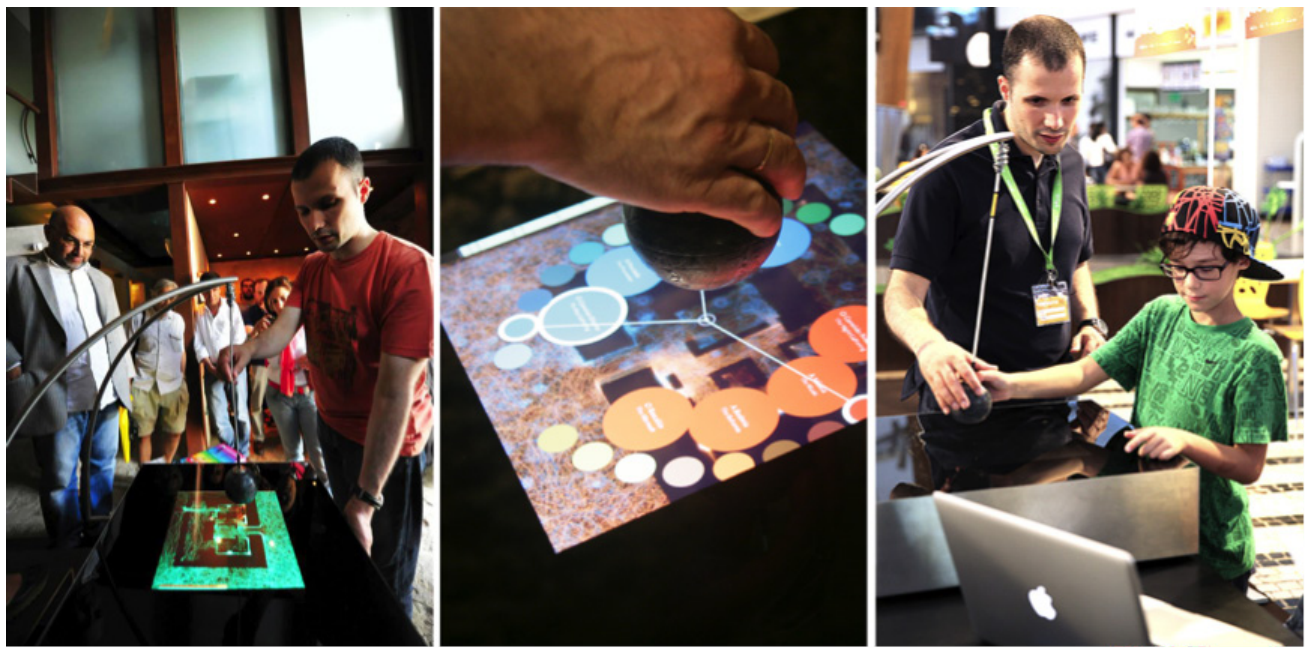

Figura 8: Experimentando o artefacto Entre o Sagrado e o Profano nas Festas de S. João d'Agra. Exemplos de composições visuais geradas pelo artefacto

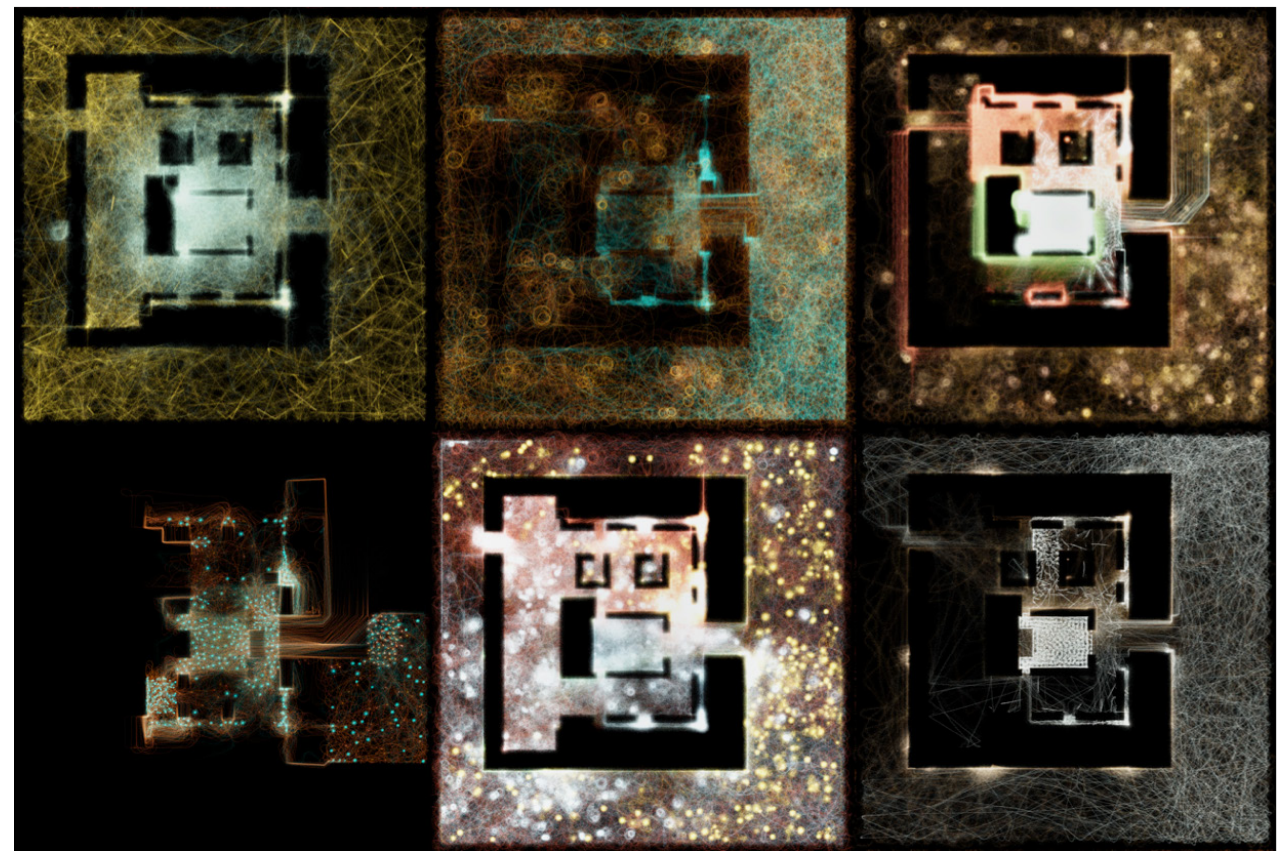

Figura 9: Exemplos de composições visuais geradas pelo artefacto

Cada imagem é construída recorrendo a princípios da arte generativa, i.e., construída através algoritmia que recebe como parâmetros elementos da interação (velocidade, posição/inclinação do pêndulo, posição relativa do utilizador face ao artefacto, etc.), a cor e a sua alteração gradual, etc. para gerar a imagem com alguns níveis de aleatoriedade controlada, tornando, de certa forma imprevisível, o comportamento dos peregrinos e, consequentemente, o aspeto visual das imagens geradas. Cada experiência é única e irrepetível. Nas Figuras 8 e 9 apresentam-se uma vista sobre a utilização do artefacto e exemplos de composições visuais geradas por via da utilização do mesmo. Este artefacto conjuga de forma vincada duas das três categorias dos artefactos de arte e cultura digital (interatividade, aleatoriedade controlada). 


\section{DA ESTÉTICA DOS ARTEFACTOS COMPUTACIONAIS}

Qualquer discussão sobre a estética ou os discursos estéticos inseridos em contextos de práticas contemporâneas, abarca necessariamente o pensamento de Kant, quando realiza uma profunda análise da arte e do seu impacto na vida do ser humano, diferenciando as questões relacionadas com a arte, propriamente dita, a forma dos juízos de caráter estético, sobre objetos de arte e outros; e aquelas questões de natureza mais teórica. Kant procurou definir conceitos basilares da estética como hoje a entendemos, seja a imanência dos objetos, a receção e representação, as limitações da apreensão, o papel do tempo e espaço, do sujeito e da sua história e sensibilidade, etc.:

temos querido provar que todas as nossas intuições só são representações de fenômenos, que não percebemos as coisas como são em si mesmas, nem são as suas relações tais como se nos apresentam, e que se suprimíssemos nosso sujeito, ou simplesmente a constituição subjetiva dos nossos sentidos em geral, desapareceriam também todas as propriedades, todas as relações dos objetos no espaço e no tempo, e também o espaço e o tempo, porque tudo isto, como fenômeno, não pode existir em si, mas somente em nós mesmos. Para nós é completamente desconhecida qual possa ser a natureza das coisas em si, independentes de toda recetividade da nossa sensibilidade. Não conhecemos delas senão a maneira que temos de percebê-las; maneira que nos é peculiar; mas que tão pouco deve ser necessariamente a de todo ser, ainda que seja a de todos os homens. (Crítica da Razão Pura, Kant, citado em Gil, 1992, p. 75)

Ou seja, Kant está na génese da definição de experiência significativa, da contemplação estética, em voga na teoria e prática das várias artes contemporâneas, que com Duchamp (1966), Giannetti (2012) ou Routio (2003), se expandem para definições em torno do artefacto e da perspetiva polissémica que o mesmo pode espoletar no observador, levando-o a assumir outros papeis, incluindo o de cocriador do próprio objeto apreciado. Os artefactos de arte e cultura digital não assumem apenas a forma de expressão ou declaração da subjetividade humana, mas são parte indissociável das afeições do espírito.

No entanto, a arte e cultura digital, na aceção que lhe é dada por Machado, não se pode confinar à deriva da produção industrial, em massa, de artefactos vocacionados apelas para os estímulos de prazer, das afeições fugazes, sob pena de se perder o desiderato maior da arte na promoção do questionamento, da reflexão e da reverberação dos temas fundacionais da nossa razão de existir como individuo, sociedade, humanidade e como universo. Urge, portanto, buscar e construir uma estética dos meios digitais que assuma e mantenha este desiderato, um processo em andamento e que, por definição, nunca terminado:

o desafio atual da artemídia não está, portanto, na mera apologia ingênua das atuais possibilidades de criação: a artemídia deve, pelo contrário, traçar uma diferença nítida entre o que é, de um lado, a produção industrial de 
estímulos agradáveis para as mídias de massa e, de outro, a busca de uma ética e uma estética para a era eletrônica. (Machado, 2004, p. 6)

Daqui advém que a estética dos artefactos computacionais integra ou desdobra-se nas várias estéticas do artefacto mediador de experiências significativas junto de um público interventivo, tomado como pessoa individual ou em grupo. Como frisado por Giannetti, tratam-se de estéticas das experiências participativas e interativas:

a receção da arte assume uma relevância peculiar a partir da relação original entre as pessoas e as obras mediante interfaces técnicas. A realidade virtual, a vida artificial e a inteligência artificial como sistemas incorporados à arte pressupõem novas experiências participativas e interativas, que permitem integrar o espectador no contexto da obra. São modelos de um tipo de entorno tecnicamente ativado, no qual somos sempre parte do sistema que observamos e com que interagimos. O diálogo entre obra e espectador se estabelece não só sobre a base da linguagem ou da reflexão, mas, sobretudo, de uma maneira prática e intuitiva, no sentido circular da comunicação, na medida em que se estimula a própria ação do público no entorno da obra. (Giannetti, 2012, p. 23)

Os artefactos de arte e cultura digital incorporam as várias estéticas relacionadas com as experiências significativas que proporcionam, quando confrontam conceitos fundamentais relacionados com as afeições do espírito, da emoção, do sagrado, da contemplação (incluindo a dimensão do sagrado), da originalidade, da complexidade, da ordem, etc. acrescidas das dimensões da aleatoriedade, da virtualidade e da interatividade, onde a técnica cede o seu lugar ao meio e contexto onde a experiência se concretiza. Outras características são-lhe comuns, nomeadamente:

- o efémero e volátil, quando o artefacto, em parte ou no todo, é constituído por componentes de existência fugaz, ainda que sem prejudicar os tempos adequados à realização da experiência;

- a sociabilidade e as experiências em rede, quando o conjunto de saberes e práticas acumulados num determinado contexto cultural ou de grupo de interesse servem de sustento e valorização da experiência de contemplação estética;

- a aprendizagem, quando o artefacto proporciona processos de aprendizagem;

- os jogos e o ludismo, quando o artefacto assume dimensões de jogo e entretenimento;

- o pós-humano, quando o artefacto assume características próprias de uma entidade inteligente artificial e autónoma, um sujeito não humano "capaz" de criar;

- a estética própria, a liberdade de definir critérios capazes de avaliar a sua própria criação.

A estética dos artefactos computacionais em arte e cultura digital reveste-se assim de características de natureza multi-, inter- e transdisciplinar onde a arte se cruza com a ciência e a tecnologia, almejando-se que a própria experiência proporcionada possa também abarcar outras dimensões de índole filosófico ou mesmo existencial. Estes 
artefactos representam, em última instância, manifestações de uma contemporaneidade eclética, plural e complexa.

\section{REFERÊNCIAS BIBLIOGRÁFICAS}

Barradas, M. T.; Coelho, J. P. \& Tavares, M. E. (2014). "Tecn made in" têxtil. Invisibilidades, 7, 72-80. Retirado de https://repositorioaberto.uab.pt/bitstream/10400.2/5702/1/Editorial_Invisibilidades_n7.pdf

Cox, C. (2009). Sound art and the sonic unconscious. Journal Organized Sound, 14(1), 19-26.

Dominguez, M.; Paulino, F. F. \& Silva, B. M. (2014). Between the sacred and the profane in the S. João d'Arga's Festivities: A digital art installation. International Journal of Creative Interfaces and Computer Graphics, 5(1),1-20. doi: http://dx.doi.org/10.4018/ijcicg.2014010101.

Duchamp, M. (1966). The creative act. Lecture at the Museum of Modern Art, New York. Art and Artists, 1(4).

Eco, H. (1962). The open work. Harvard: Harvard University Press.

Giannetti, C. (2012). Estética digital - Sintopia da arte, a ciência e a tecnologia. Belo Horizonte: Nova Vega.

Gil, F. 8Ed.) (1992). Recepção da crítica da razão pura: Antologia de escritos sobre Kant (1786-1844). Lisboa: Fundação Calouste Gulbenkian.

Grau, O.(2003). Virtual art - From illusion to immersion. Cambridge: Massachusetts: The MIT Press.

Greene R. (2005). Internet art. Londres: Thames \& Hudson Ltd.

Guerra, I. \& Paulino, F. F. (2010). O documentário etnográfico: Da memória ao produto turístico. Polytechnical Studies Review, VII (14), 123-135.

Lopes, D. M. (2010). A philosophy of computer art. Routledge: Taylor \& Francis Group.

Machado, A. (2004). Arte e mídia: Aproximações e distinções. Revista da Associação Nacional de PósGraduação em Comunicação, 1.

Manovich, L. (2002). The language of new media. Cambridge: Massachusetts: The MIT Press.

Marcos, A.; Branco, P. \& Carvalho, J. (2009). The computer medium in digital art's creative development process. In J. Braman \& G. Vincenti \& G. Trajkovski (Eds.), Handbook of Research on Computational Arts and Creative Informatics (pp. 1-15). Hershey, Pennsilvania: IGI Publishing.

Marcos, A. \& Zagalo, N. (2011). Instantiating the creation process in digital art for serious games design. Journal Entertainment Computing, 2(2), 143-148.

Marcos, A. F. (2012). Instanciando mecanismos de a/r/tografia no processo de criação em arte digital/computacional. Invisibilidades, 3, 138-145. Retirado de http://repositorioaberto.uab.pt/ handle/10400.2/2204

Quinn, B. (2012). Fashion futures. Londres: Merrell Publishers.

Quintas, R.; Marcos, A. \& Tavares, M. (2015). Escultura Présence: um sistema tridimensional de interação sonoro-corporal. In P. Meneses (Ed.), Atas do $22^{\circ}$ Encontro Português de Computação Gráfica e Interação - SciTecIn/EPCGI 2015 (pp. 4-12). Coimbra: Instituto de Sistemas e Robótica. Retirado de http://www.isr. uc.pt/epubs/epcgi2015.pdf

Paul, C. (2005). Digital art. Londres: Thames \& Hudson Ltd. 
Routio, P. (2003). Arteology: Semiotics of artifacts. Retirado de http://158.132.155.107/posh97/private/ Arteology/Arteology.pdf

\section{NOTA BIOGRÁFICA}

Adérito Fernandes Marcos é Professor Catedrático da Universidade Aberta; Fundador e Diretor do Doutoramento em Média-Arte Digital, uma oferta em associação da Universidade Aberta e Universidade do Algarve; membro integrado do CIAC - Centro de Investigação em Artes e Comunicação; investigador colaborador do INESC-TEC Instituto de Engenharia de Sistemas e Computadores, Tecnologia e Ciência; e Presidente da Artech-International - Associação Internacional de Arte Computacional.

E-mail: aderito.marcos@uab.pt

Universidade Aberta, Palácio Ceia, Rua da Escola Politécnica, 147, 1269-001 Lisboa, Portugal

* Submetido: 10-03-2017

* Aceite: 28-04-2017 